\title{
PREFACE TO THE SECOND ENGLISH EDITION
}

A day after the storming of the Capitol in Washington, D.C., on 6th January 2021, I received an e-mail from Stephen Greenblatt. Commenting on the insurgents' determination to document and broadcast their enterprise, he struck me as unerring in his conclusion: “This is an image act!" What had occurred in Washington can indeed be understood as a powerful instance of the entity I have sought to characterise as the "substitutive image act". For those engaged in this onslaught upon the body politic of the USA, the visual record of this outrage was of more significance than the event itself. For a while the availability of this record, across America and around the world, was in real danger of provoking a far greater state of emergency than that which had already come about. This incident shows how easily, in our age of digital media, bodies and images may merge; but it also reveals how necessary it is to comprehend this type of substitution - of the image for the body, and of the body for the image - as a categorical form of the history of images and, in turn, how essential it is to analyse this phenomenon in order, as Aby Warburg would say, to achieve a salutary distance between it and ourselves.

It is thus all the more important to focus attention also upon the image act in its "schematic" and in its "intrinsic" forms. It is in the name of enlightenment adequate to an era in thrall to the visual that we need take these dimensions into account. A failure to acknowledge the autonomous surplus of images not fully absorbed within the conscious awareness of the observer means surrendering ourselves to its power. Guarding against such an outcome is the purpose of this book. 
